ARTICLE

DOI: $10.1057 /$ s41599-018-0119-3

\title{
Evidence and morality in harm-reduction debates: can we use value-neutral arguments to achieve value-driven goals?
}

\author{
Giulia Federica Zampini i ${ }^{1}$
}

\begin{abstract}
It is common to argue that politicians make selective use of evidence to tacitly reinforce their moral positions, but all stakeholders combine facts and values to produce and use research for policy. The drug policy debate has largely been characterised in terms of an opposition between evidence and politics. Focusing on harm reduction provides useful ground to discuss a further opposition proposed by evidence advocates, that between evidence and morality. Can evidence sway individuals from their existing moral positions, so as to "neutralise" morality? And if not, then should evidence advocates change the way in which they frame their arguments? To address these questions, analysis of $N=27$ interviews with stakeholders actively involved in drug policy and harm reduction debates in England, UK and New South Wales, Australia, was conducted. Participants' accounts suggest that although evidence can help focus discussions away from values and principles, exposure to evidence does not necessarily change deeply held views. Whether stakeholders decide to go with the evidence or not seems contingent on whether they embrace a view of evidence as secular faith; a view that is shaped by experience, politics, training, and role. And yet, morality, values, and emotions underpin all stakeholders' views, motivating their commitment to drug policy and harm reduction. Evidence advocates might thus benefit from devising strategies to morally and emotionally engage audiences. This paper aims to develop better tools for analysing the role of morality in decision-making. Using tools from disciplines such as moral psychology is relevant to the study of the politics of evidence-based policymaking.
\end{abstract}

\footnotetext{
${ }^{1}$ The School of Law and the Centre for Criminology, University of Greenwich, Queen Mary Building room 217 Old Royal Naval College Park Row, London SE10 9LS, UK. Correspondence and requests for materials should be addressed to G.F.Z. (email: G.F.Zampini@greenwich.ac.uk)
} 


\section{Introduction}

oo often, support for evidence-based drug policy has been framed in terms of opposites. In this characterisation, evidence is portrayed as the clean, scientific, neutral and value-free solution to a dirty, partisan, ideological, and valueladen politics. This article transcends this dualistic view by introducing another element-that of morality. The concept of morality is deployed as a framing device for understanding harm reduction debates in drug policy. Throughout the paper, the term evidence refers to scientific evidence, or evidence which has been produced by deploying established scientific methods in a given field. Evidence is organised hierarchically (Petticrew and Roberts, 2003), and although there are some differences across fields of inquiry, evidence hierarchies tend to culminate with systematic reviews of Randomised Controlled Trials. Evans (2003) suggests that evidence hierarchies have mostly been constructed through an exclusive focus on effectiveness of an intervention. A more nuanced discussion is in order, but for the sake of brevity, the focus will remain on evidence of effectiveness of given interventions as a matter of political priority.

The concept of harm reduction, and particularly its proclaimed moral ambiguity, is reflected upon. A rhetorical shift away from a formal commitment to harm reduction-which entails reducing drug-related harm to users-and towards promoting abstinence and recovery-which entail abstaining from drugs and reaching sobriety-has reinserted elements of morality that had remained latent in UK and Australian drug policy (Home Office, 2010; Berridge, 2012; Lancaster et al., 2015). Although harm reduction began as a moral and political crusade to advocate for the rights and health of drug users, it was later incorporated into a much less openly moral model that emphasised economic arguments for drug treatment in order to justify them publicly and politically (Roe, 2005). Scientists, advocates, and practitioners deployed a value-free rhetoric to justify their endorsement of harm reduction, shunning values in favour of cost-benefit-driven, evidencebased rigour. Some commentators have argued that defending an amoral position is preferable because it tacitly allows for a diversity of moral positions, whilst winning political backing (Keane, 2003; Beirness et al., 2008). Others disagree based on limited achievements and loss of political control, arguing instead for an openly moral and humanist stance (Hathaway, 2001; Ezard, 2001; Hunt, 2004; Pauly, 2008).

In this context, evidence is relied upon as a tool to de-politicise and de-moralise harm reduction debates. Yet the potential of evidence to affect deeply held views is called into question: can evidence sway individuals from their existing moral positions, so as to "neutralise" morality? And if not, then should evidence advocates change the way in which they frame their arguments? To address these questions, I analysed data from 27 interviews with stakeholders involved in drug policy advocacy, research, lobbying and decision-making in England, UK and New South Wales, Australia. Both countries, along with all Anglophone countries, feature as 'liberal' in welfare regime typology categorisation (Esping-Andersen, 1990). Approaches to welfare define the relationship between state and citizen. In liberal states, there is a clear tendency to place the burden of responsibility on the individual, which is visible in established welfare policies such as means-testing, workfare models, and punitive sanctions against the unemployed (MacGregor, 1999; Dee, 2013; Eriksson and Pratt, 2014). These shifts have become even more pronounced since UK Conservatives and Australian Liberals have been in government (Taylor-Gooby, 2016; Deeming, 2017). Analysis of these two cases can give way to theoretical contributions that may be relevant in the context of other Anglophone countries.

In the following article, instances where evidence was used selectively to support stakeholders' deeply held views will be discussed, exploring to what degree this was instrumental or value-based (or both). Literature on the use of evidence in policy has largely focused on instrumental selection of evidence to support a political or strategic aim, but less on how this relates with stakeholders' value-based, moral positions. Instances where exposure to evidence enabled individuals to change their views on drug policy issues deserve some attention, because, on the surface, this fulfils the wishes of evidence advocates to overcome politics and morality as barriers to evidence-based policymaking. However, the conflation of morality and moralism by stakeholders leads to a widespread supposition that morality only exists on the side of the argument that is opposed to that backed by evidence. This is both problematic and limiting. Liberal moral principles. alongside values, emotions, and experiences, underpin stakeholders' commitment to harm reduction. Whilst policy analysis would benefit from further engaging with morality, evidence advocates need to reflect on their own morality, for the purposes of framing arguments and for engaging audiences.

Findings suggest that selection of evidence is not merely motivated by instrumental objectives, but rather underpinned by stakeholders' values and existing moral positions. While evidence might affect people's understandings of drug policy issues, it does not necessarily change their deeply held views. People's values and morals shape perceptions, thus making fundamental shifts in policy much more difficult to achieve despite available evidence. Stakeholders' commitment to drug policy and harm reduction seems to be motivated by direct experience or emotional exposure to issues drug users face. Interestingly, some participants suggested that if scientific evidence is accompanied by exposure to personal stories or direct experiences, stakeholders are more likely to engage by way of empathy. This is discussed with reference to moral psychology literature, and particularly moral foundations theory, which offers some insight into how morality operates and how it can be mobilised, potentially providing advocates with ideas about how to engage their audiences.

Morality, policy and harm reduction. Morality is an instrument that individuals use to order practices and activities into categories of first principles, or right and wrong (Fischer, 2004). Morality is made up of values, beliefs, emotions, experience, principles and deliberations. It is constructed in dialogue between the individual and the multiple environments the individual experiences. In debates about evidence-based policymaking, morality is often mistaken with moralism; hence, it is conceptualised as subjective, reactionary, and inimical to progressive, sound, objective reasoning. Yet, morality underpins all reasoning and has no single political or ideological valence (Haidt, 2013; Hunt, 1999). Studies in moral psychology (Lakoff, 1996; Haidt, 2013) and sociological studies of morality (Hunt, 1999) are useful reminders that morality is multiple. Haidt (2013) posits that what is regarded as moral by a liberal might be viewed as immoral by a conservative because liberal and conservative moralities are fundamentally different; that is, different moral foundations underpin political positions. Such foundations are primary in shaping people's views and feelings about particular subjects. Some of the perspectives reviewed in this article originate in the US and are grounded in moral psychology. This can be perplexing at the level of terminology. In US moral psychology literature (Graham, Haidt, and Nosek, 2009; Haidt, 2013; Lakoff, 1996), 'liberal' and 'conservative' are used as shorthand ideal-types to denote a propensity toward certain moral positions. In other literature, these may sometimes be referred to through the authoritarianism/ libertarianism dichotomy (Evans, Heath, and Lalljee, 1996; Flanagan and Lee, 2003; Ray, 1982; Tilley, 2005). We know that 
political and moral positions are not two-dimensional; we may thus observe an individual endorsing conservative economic policy whilst being socially libertarian. Conversely, another individual may endorse socialist economic policies whilst being socially conservative. For this discussion, liberal and conservative positions are not intended as straightforward political affiliations, nor as political philosophies, but as moral positions associated with particular moral foundations.

In the United States, there is a literature on morality policy that surfaced in the mid-to-late 1990s (Haider-Markel and Meier, 1996; Meier, 1999; Mooney, 1999). This literature was overlooked until recently, when a number of scholars began applying the concept in the European context (Engeli, Green-Pedersen, and Larsen, 2013; Heichel, Knill, and Schmitt, 2013; Knill, 2013). Morality policy is here defined as a field where decisions are more often based on first principles (right and wrong). In such fields, significant policy change is regarded as harder to achieve because contrasting positions are underpinned by conflicting, deeply held views (Knill, 2013; Meier, 1999; Mooney, 1999). Morality policy is thus characterised by 'clashes of first principles' and 'not [...] technical debate about whether the policy will "work" or not' (Mooney, p 676).

Drug policy scholars and evidence advocates have long popularised the concept of 'what works', derived from evidence-based policy precepts, in order to move the debate away from first principles and towards pragmatic solutions and compromise (i.e., Monaghan, 2010; Stevens, 2007; Strang et al., 2012). Knill (2013) argues that drug policy debates happen on two levels: a deeper level of first-principled positions, as well as a surface level concerned with practical implications, impact and "what works". Policymakers in drug policy debates are often accused of selecting evidence in a political-tactical manner (Stevens, 2007; Naughton, 2005). In the literature on models of evidence utilisation, a political-tactical model features selection of evidence that is motivated by a combination of strategic, political and interest-driven concerns. In this view, evidence is used as ammunition to justify action or inaction on a given issue, in an instrumentally rational manner (Monaghan, 2011). This creates antagonism between evidence advocates and policymakers.

Knill (2013) proposes a different reading. He categorises drug policy as a latent morality policy, where first-principled positions can be strategically disguised or couched in debates about impact and pragmatic solutions to problems, thus hiding morality through evidence. This can be usefully applied to harm reduction. Whilst harm reduction is driven by liberal moral values such as tolerance, belief in universal health, individual and human rights and promotion of civil liberties (Hathaway, 2001; Marlatt, 1996), these values are underplayed in public health and in policy debates. In this context, evidence is called upon to promote harm reduction policies in an amoral, value-free manner (Strang et al., 2012). Some believe that opting for value-neutral arguments by framing them as evidence-based wins them political backing, increased respect, and credibility (Beirness et al., 2008). By standing on the shoulders of evidence, 'harm reduction avoids moral challenges to prohibition in favour of cost-benefit analyses' (Hathaway, 2001, p125), eschewing criticism and bypassing the moral and the political.

The discussion between Hathaway (2001) and Keane (2003) exposes problems that have remained latent in harm reduction as a movement and as a practice since its inception. Hathaway calls for the need to discard value-neutrality in favour of a value-laden, moral commitment to harm reduction principles. He argues that although there appear to be clear advantages to framing harm reduction in value-free terms, its pursuit is ultimately weakened by the lack of recognition of the shared values and principles that inform it. Hathaway's conclusion rests on the premise that 'harm reduction style rhetoric, with its illusion of neutral standing in the name of empirical reason, is strategically flawed insofar as it disavows the moral footing needed to address prohibitionism as both an immoral and irrational approach to drug policy' (Hathaway, 2001, p 135).

In response to Hathaway's challenge, Keane takes a rather opposing stance. She argues that 'one of the distinguishing elements of harm reduction has been its commitment to an amoral approach to drug use. This may not be achievable in practice, but it is a powerful rhetorical intervention in the highly moralised landscape of drug debate' (Keane, 2003, p 227). Following this logic, it seems clear that harm reduction is assumed to be stronger when value-neutral in appearance because it can rest on the higher grounds of evidence rather than having to descend into messy politics and morality. This amoral and evidence-based take on harm reduction becomes an effective advocacy strategy 'by framing drug use as a technical and public health problem rather than a moral issue' (Keane, 2003, p 229).

Although public health problems can be framed as technical rather than value-oriented, they ultimately require normative engagement with values and principles. According to Roe, the rift in harm reduction reflects a historic tension within the movement, between a moderate and medically dominated politics of health promotion among marginalised individuals on one hand, and an activist, transformative politics pursuing deeper structural changes on the other (Roe, 2005, p 244). This tension will become apparent in what follows, as advocating for drug users' health, not their rights (Hunt, 2004), figures as a morally and politically palatable stance for stakeholders.

\section{Methods}

For this paper, I analysed data from 27 interviews conducted in England, UK, and New South Wales, Australia. Interviews were carried out as part of a $\mathrm{PhD}$ project focusing on understandings and uses of evidence in drug and prostitution policy (Zampini, 2016). There is a shared political and cultural heritage between the UK and Australia, including the key elements of language and the similarities in their legal system, which work well to underpin a most similar comparative design. However, potential contrasts emerge from the diversity in the structure of their respective political systems. Australian federalism is well rooted in the country's political structure. Similarly, the centralism of UK politics, despite more recent steps toward devolution and localism, is still predominant (Zampini, 2014). With the UK undergoing structural changes, devolving powers to its constituent parts, this discussion becomes even more relevant in drug policy (Duke and Thom, 2014; Haydock, 2015). This process entails the possibility of assessing propositions around the relative independence of localities to pursue policies which deviate from national and international directives or for the possibility of "bottom-up" initiatives to become established, which has been done elsewhere (Zampini, 2016). This, alongside logistical and practical ease, is the main reason smaller political units of analysis, namely England and New South Wales, were selected.

Participants were chosen due to their direct involvement in policy-making, policy-relevant or policy-related research. Ethical approval for carrying out interviews was given by the University of Kent ethics committee. At first, participants were identified through documents including academic and grey literature, evaluations and reviews of relevant interventions. Participants were purposively identified and recruited through chain-referral. Discussions verged on prominent issues in drug policy, including harm reduction interventions, and particularly drug consumption rooms. The analysis was an iterative process, allowing for the principle of emergence (Archer et al., 2013) to guide 
investigation, whilst utilising existing models of the use of evidence in policy as starting points, through the logic of adaptive coding (Layder, 1998).

Participants ranged from serving parliamentarians to grassroots-level advocates. This not only implies diversity in the sample, it also signifies differences of status, degree of involvement in individual issues, and understandings and deployment of evidence. Participants' varied professional backgrounds were grouped into three overarching categories: researchers (includes medical/practitioners), politicians (includes political advisors, civil servants and bureaucrats) and advocates (includes knowledge brokers). However, categories often intertwined, with some participants belonging to two or more. Quotes have been assigned using numbers preceded by the identifiers AU for Australia and UK for Britain, and clearly stating the participants' professional background(s). Identifying participants' multiple professional background is regarded as relevant because it contributes to understanding their position vis-a-vis their experience and training.

Whereas the uses and understandings of evidence were set themes in the interviews, which led to establishing codes derived from existing models of evidence utilisation (linear; enlightenment; political-tactical; interactive; evolutionary; dialogical and processual models as discussed by Weiss, 1979 and Monaghan, 2011), values, emotions, experience, and beliefs were emergent themes in participants' accounts. These themes were conceptualised as belonging in the realm of morality. Participants variously referred to morality, moral positions, and value-based, emotional or cognitive biases as barriers to the proper use of evidence in policy. This warranted reflection and analysis of the proposed dichotomy between evidence and morality.

Selective use of evidence: no mere instrumental cherry-picking. Participants saw the production and presentation of evidence as strategically and politically necessary. Beyond that, evidence was purported to have neutralising properties in what was regarded as a highly polarised domain. However, most participants argued that stakeholders treat evidence selectively. Yet their selective attention is not simply instrumental, but shaped by their moral values, politics, experience, professional training, and occupation. Participants mostly agreed that evidence could only go so far in informing people's views, because:

people will latch on to policy recommendations and conclusions that fit with [...] their view of the world [...]. People have an underlying ethos of values and they frame their interpretation of the evidence around that. (UK Researcher/ Knowledge Broker 23)

Here, the participant stresses interpretation and framing of evidence as filtered through one's ethos of values. In the case of the UK Home Affairs Select Committee on drugs (2012), the Home Secretary had a clear agenda to criticise Portuguese drug policy, which was identified as:

selective use of evidence in order to support a prior position, rather than seeking to look at the evidence [...] with a purported objectivity. (UK Politician 19)

In this instance, the Home Secretary framed her claims as based on evidence, or lack of evidence, as a justification for dismissal of the Portuguese approach. Can a political-tactical aim be easily distinguished from a moral, value-based opposition? The Home Secretary's position might have been political-tactical in aim (Weiss, 1979), though at the same time it may have been founded upon disagreement on first principles (Mooney, 1999). It appears that stakeholders can satisfy both their strategic interest and their moral stance, without needing to make their moral stance manifest, by claiming that their position is evidence-based.

Few stakeholders are comfortable with overtly stating their moral position in the drug policy debate. Thus, they keep the focus on evidence, while engaging in debates about instrumental objectives. This is a typical trait of latent morality policy (Knill, 2013), where selective use of evidence allows stakeholders to stick with their pre-held view whilst justifying it through scientific authoritativeness, or lack thereof. Thus, evidence is not simply selected instrumentally, which would be political-tactical in aim:

Where evidence supports a particular policy, great. When it contradicts it, then people would be less interested. [...] Some degree of selective attention to what supports our world view (UK Researcher/Knowledge Broker 25)

The idea of selective attention is useful because it suggests that individuals order and weigh evidence differently, not necessarily according to the evidence quality per se, but according to their deeply held views based on their principled positions (Zampini, 2016).

Still, the production and presentation of evidence was regarded as strategically and politically necessary, and beyond that, evidence was believed to have neutralising properties. Based on participants' responses, the targeted production of evidence was useful in the debates surrounding the establishment and continuation of a Medically Supervised Injecting Centre in Sydney:

it was the neutralising factor of having [...] that evaluation

[...] going on, it was producing reports all the time... it was just forming that wall around the centre that shielded it.

(AU Political Advisor 8)

In this case, evidence was useful to "neutralise" a politically heated debate surrounding a controversial intervention. In other words, the framing of this debate in terms of evidence of effectiveness, rather than values such as human rights, was politically useful. The reliance on evidence to shelter interventions which are politically difficult to justify was noted by participants in relation to other harm reduction policies including needle and syringe exchange and opiate substitution treatment.

Exposure to evidence appeared, in some cases, to render people less entrenched and more willing to engage in debates. In one case where the participant had led a DELPHI exercise with a diverse range of stakeholders, they noted that:

some people in this world [...] are just so entrenched, but the majority of people who did come from a range of different perspectives were able to move forward and engage sensibly. (UK Researcher/Civil Servant 26)

Sensible engagement in debates might refer to people's ability to shift their focus away from their deeply held views and towards instrumental discussion about interventions (Knill, 2013), potentially fostering understanding and compromise. The same participant inferred this when stating:

if people could actually discuss the evidence and their different views on it and have [...] a discussion that doesn't necessarily attack people's perspectives then [...] you can make progress. (UK Researcher/Civil Servant 26).

Here, the participant makes a distinction between discussing the evidence and discussing people's perspectives, which would imply directly engaging with their values and moral positions.

In contrast with the idea that actors, and particularly those whose political stakes are higher, use evidence selectively to make political gains while supporting their pre-held views, there are instances of powerful actors in both countries who took the 
evidence on board even when it contradicted their existing position. Below is one example:

one Drug Minister said to me 'look, I went into this thinking one thing, but when the $\mathrm{ACMD}^{1}$ came back to me with their facts and their explanations, I took that on board, acted on their conclusions, on their recommendations', so even though they had [...] different values going into it, they didn't impose that. (UK Knowledge Broker 23)

This suggests that some stakeholders place evidence above values because they believe that evidence is value-free, or at least less value-laden than their own moral position. In such cases, upholding a fact/value distinction offers clear political gains for evidence advocates.

Participants believed that evidence-based policy was the only rational and just principle on which to base drug policy, and as such they were all nominally committed to it. As Boswell (2018) argued, evidence-based policy is the 'secular faith' that binds stakeholders together, and a very useful myth to uphold and frame to deploy. However, participants' accounts suggest a propensity for some stakeholders to associate moralism with views which are opposed to those they themselves hold. There are many examples of this in the public domain. The Global Drug Policy Commission published its latest report, introducing it with the following paragraph:

'Drug policy reforms have been difficult to design, legislate or implement because current policies and responses are often based on perceptions and passionate beliefs, and what should be factual discussions leading to effective policies are frequently treated as moral debates. The present report aims to analyse the most common perceptions and fears, contrast them with available evidence on drugs and the people who use them, and provides recommendations on changes that must be enacted to support reforms toward more effective drug policies.' (Global Commission on Drug Policy, 2017)

There is a tendency to view, or at least present, the other's position as moral, and one's own position as evidence-based. Participants would thus place evidence on one side of the spectrum, and morality and politics on the opposite side, reinforcing the antagonism between evidence advocates and policymakers:

there is so much around the drugs debate that is morally and ideologically driven, that often I feel that politicians actually don't care what the evidence base is (UK Knowledge Broker 25).

The case of expert opposition to the Medically Supervised Injecting Centre in Sydney provides an example. In the quote below, the participant doubts the credibility of those experts who opposed the intervention, suggesting that, had they been "true" experts, they could not possibly have opposed it, so they must be using their scientific expertise to disguise their moral opposition:

we also had so-called experts who opposed the injecting centre [...] I say so-called because I would doubt the validity of some of the experts that criticised the injecting centre (AU Political Advisor 8).

Often, evidence advocates portray themselves as amoral, and contrast morality with evidence, and beliefs and perceptions with factual discussions centred on effectiveness. This strategy is perceived as successful because morality is conceptualised as moralism, and therefore seen as reactionary, emotional and subjective, whereas evidence is conceptualised as progressive, rational and objective.
In some cases, robust evidence of effectiveness of an intervention is not accumulated until that intervention is already in place on a reasonably wide scale. Early Needle and Syringe Programmes were rolled out before robust evidence of their effectiveness was accumulated. Today,

even without a randomised controlled trial for needle syringe programmes, we still can draw a conclusion that needle syringe programmes do reduce HIV infection [...] and we can say that with a very high degree of certainty in an area which is a minefield of emotional antagonism (AU Medical Researcher 2)

Here, the participant exposes how the evidence trumps emotional antagonism around the issue of needle and syringe distribution; in other words, how evidence wins over emotion and values. However, this bypasses the values and emotions which would have motivated harm reduction activists to start needle exchange as an informal practice based on epidemiological evidence alone, and prior to systematic accumulation of evidence of its effectiveness and cost-effectiveness. In Amsterdam, where the first needle and syringe programme was established in 1984, it was the local 'Junky Union' that began to informally distribute clean needles before the scheme was formally introduced by the municipal government (Coutinho, 2000, p 1387). In this instance, needle exchange appears to be motivated by a moral imperative to protect people from disease and death. It was a political initiative of civil disobedience led by those activists which Roe (2005) identified as pivotal to the creation of the movement.

The establishment of the Medically Supervised Injecting Centre in Sydney followed a similar pattern: local medical practitioners and activists started a medically supervised injecting centre illegally, partly as a strategy to gain political attention, but also because they believed that, morally, it was the right thing to do (Wodak et al., 2003; Zampini, 2014). Indeed, they could rely on evidence from other countries where the intervention was already in place, but was evidence primary in motivating their actions? Evidence alone is not sufficient to motivate an intervention. Moral and political convictions need to precede, or at least accompany, evidence of effectiveness.

Liberal morality and harm reduction. The perception that political support for harm reduction comes from economic and scientific, rather than moral grounds, was shared among participants. Harm reduction interventions appeared easier to justify, both publicly and politically, on the basis of value-for-money. An economic principle thus overrides moral concerns for the health and rights of drug users.

I used to think that people would make decisions based on things like human rights, or just people's health, but actually to make a decision [...] these days unless you've got an economic argument that also justifies it, you'll find it that much harder to get support for it. (UK Researcher/ Advocate 21)

In line with a managerialist culture dominating the UK and Australian public health sectors (Germov, 2005; Pollitt, 2016), a value-free approach to harm prevails, whereby the rational calculation of harms is carried out in economic terms (Lenton and Single, 1998, p 219). When discussing the possibility of establishing a drug consumption room in the UK, one participant stated: 'my issue with this [...] it's never been a moral one. It's a cost-effectiveness issue' (UK Civil Servant/Advocate 22). In this case, a concern for cost-effectiveness prevails over a moral concern for the health and rights of drug users as a matter of political strategy. Drug users occupy a low place in the hierarchy 
of deservingness in society (a position that is value-based, Skinner et al., 2007). This, coupled with the relatively widespread perception that drug use is immoral, renders them both structurally constrained and immoral agents, in the eyes of some (Stevens, 2011).

According to Pauly (2008), harm reduction principles address issues of social justice by understanding access to health as structurally inequitable. A liberal morality implies an acceptance that people should not be judged for their choices and behaviours. Whilst maintaining a strong normative position on the right to health, in moral terms, harm reduction remains a liberal stance given the absence of judgement toward the individual and respect toward their choice. Thus, harm reduction rests on ideas and principles rooted in universal health alongside a liberal moral attitude towards the individual. For Stevens, 'the answer to the question of whether there is a right to drug use appears to be yes. But it is a rather small yes' (2011, p 236). Judgements among harm reduction stakeholders are split, with many supporting medicalised, dependent drug use whilst denying recreational use, which is considered more morally ambiguous (McKeganey, 2011). Given the clout of science and medicine in shaping both the understanding and enabling of drug use within a public health frame, an individualistic, rights-based approach to drugs is harder to justify politically (Hunt, 2004).

Despite an overwhelming commitment to evidence as a just basis for decision-making in drug policy and harm reduction, when referring to certain aspects of drug policy such as the consequences of prohibition, some evidence advocates, who defined themselves as supporting evidence-based policy 'to a fanatical degree' (AU Medical Researcher 2), express a sense of injustice on moral grounds.

Is it fair and just that the majority who prefer, say, alcohol or tobacco, [...] wants to punish people who have a different drug preference? (AU Medical Researcher 2)

A preference entails a degree of choice, and thus expands beyond the medical to encompass rights, and even pleasure. The above statement also appeals to a fairness principle, which is a moral foundation typically mobilised by liberals (Graham, Haidt and Nosek, 2009). Prior to the establishment of the Medically Supervised Injecting Centre in Sydney, participants acknowledged that those who began running an injecting centre illegally, did so:

On the basis of an ethical belief [...] it was a competing principle which was given much higher weight than somebody else's set of principles about some universal idea [...] the good thing about harm reduction as a principle is it does allow those negotiated responses. (AU Medical Researcher 4)

This statement implies that there is a moral basis for people's decision to support harm reduction interventions, even if they do so illegally. Yet it also implies that harm reduction as a principle can accommodate moral diversity. Some participants appeared to support Keane's (2003) view that the strength of harm reduction is its apparent value-neutrality and moral ambiguity. However, as Roe (2005) noted, although harm reduction presupposes a lack of value judgement towards individuals' choices, it does still rest on the values of universal welfare and universal healthcare. As one participant put it:

Philosophically we work from a position of health for all and a belief that our target populations have traditionally had poor access [...] to healthcare and that healthcare needs to be equitable. (AU Medical practitioner 12)

Participants have emphasised the increased difficulty of gathering political support to fund treatment in times of austerity.
The economic argument against prohibition, which would emphasise states' ability to raise tax revenue from regulating drugs, has not often translated into a significant policy change in a different direction, perhaps with the exception of certain US states (Room, 2014). When referring to the money spent on the Medically Supervised Injecting Centre in Sydney, which has been the subject of multiple evaluations, one participant asked:

Why are we making such song and dance about this three million dollars when there are zillions of dollars spent across the sector and across other sectors and none of that gets evaluated? Why do we never evaluate the money that gets spent on prohibition, for example? (AU Medical Researcher 7)

The participant's frustration is motivated by the perceived hypocrisy arising from the lack of investment in the production of targeted evidence evaluating law enforcement expenditure vis-àvis successful interventions. This might indicate that value-formoney, an overriding principle in the multiple evaluations of the Medically Supervised Injecting Centre (MSIC Evaluation Committee, 2003), is not necessarily the main value which pushes drug policy in one direction or another.

In the context of a paradigm shift toward conservatism in UK politics, participants noted how drug use and addiction were reframed to fit the ideology of austerity.

Drug addiction is [depicted as] the cause of poverty. So poverty ceases to be about not having enough money, and becomes the failings of the poor and the individual. So it fits with an individualist political strand of thought and with a moral strand of thought (UK Civil Servant/Advocate 22)

In such conservative times of austerity, the abstinence and recovery arguments were mounted on moral grounds (Stevens and Zampini, 2018).

By critiquing maintenance prescribing, [the Conservatives] tick moral boxes for the authoritarian and religious right (UK Civil Servant/Advocate 22)

In this context, can advocates who subscribe to harm reduction-and its liberal moral underpinnings - challenge value-laden, moral arguments with evidence-based, value neutral ones?

Commitment to harm reduction: the power of emotional engagement. When reflecting on the influence of professional background and experience on individuals' values and attitudes, and specifically the differences between advocates and policymakers, one participant noted that:

Most of the people in NGOs are there because of some belief system they have, [...] and they are committed to it, [...] whereas conversely most people in governmental structures are by their nature not particularly driven by the subject they are dealing with. (UK Advocate/Knowledge Broker/Civil Servant 20)

This reveals the common-held assumption that advocates are subject and value-driven, whereas politicians and bureaucrats are not. However, interview data suggests that the degree of individuals' engagement with drug policy and harm reduction will depend on the extent and nature of their experience and exposure to issues drug users face. If that individual is a Minister, a Premier or a Prime Minister, the likelihood that drug policy and harm reduction will figure highly on the political agenda appears to increase proportionately. For example, in New South Wales, the fact that Premier Bob Carr's brother died of a drug overdose 
apparently pushed drug policy higher on the political agenda, which favoured the 1999 Drug Summit initiative, as well as the establishment of a ground-breaking harm reduction intervention as the Medically Supervised Injecting Centre (Zampini, 2014):

The Premier, who had lost a brother to drug overdose, who was quite ambivalent, he is quite a conservative person Bob Carr, but $[. .$.$] he put aside his own feelings, and [...] he let$ it go through. [...] If he had said no, that was it. Game over, right from the start. (AU Political Advisor 8)

In this quote, the participant suggests that the premier's feelings, underpinned by his conservative stance, would have acted as a barrier to the implementation of the intervention. The question remains, if the Premier's brother had not died of an overdose, would he have been able to empathise, to relate with the reality of a person who uses drugs, and consequently dedicate time and resources to drug policy reform?

In a similar vein, Australian Prime Minister Bob Hawke (1983-1991) had instigated commitment to drug policy reform and harm reduction at the federal level, bumping it up the political agenda, because of his personal story:

His daughter had a heroin addiction, and he broke down on $\mathrm{TV}$ and cried, and that was the start of a national campaign against drug abuse, based on the personal situation of the Prime Minister at the time, the one he was facing at home with one of his kids, so that was enough to drive change... That was the start of the national strategy, it was driven out the PM's office. (AU Knowledge Broker 3)

For an individual to dedicate attention to this area, it appears that a moral and emotional commitment is somewhat necessary. This is also true for scientists, who might choose to engage in a form of research activism underpinned by a moral commitment to research for social change and justice, because:

It's not [...] a "nice" area to do research, [...] I mean these are people's lives! (AU Medical Researcher 5)

Beneath the commitment to a rigorous, medical model to run services focusing on drug-using clients, there is a shared belief that the health needs and rights of these populations are generally not well catered for and that a principle of harm reduction should underpin these services:

It all came together to give me an incredible interest in sex, drugs and the public health issues around those [...] our system didn't cater well to those populations [...] I was quite inspired by the model that was recommended [...] which would be non-judgemental, respectful, harm reduction in its focus (AU Medical Researcher 7)

In this instance, harm reduction is understood as a manner to tackle structural inequities and pursue change. This is consistent with other participants' accounts of their initial involvement in this area. Participants seem to pick their subject not only out of training or necessity, but out of a value commitment. Although stakeholders with a political or public service background are by their nature generalists, and do not get to pick their subject, they will choose to be more or less invested in particular issues depending on their values and experience.

Participants broadly recognise that human beings, including researchers, are subject to the limitations brought about by their beliefs and morals:

There are some things that you won't necessarily change which may be your [...] personal beliefs and morals and they do influence how you perceive evidence or react to it.

(UK Researcher/Civil Servant 26)
This is not only the product of politics or ideology, but also the result of emotional and cognitive biases (Parkhurst, 2016), which, despite being recognised, continue to be portrayed as negative because irrational.

The human mind is perhaps not as rational as we might wish and is subject to various biases and preconceptions and different ways of being influenced by data and linking those to consistency with an existing view of the world (UK Politician 19)

Positivist notions, such as the reason/emotion dualism, limit the possibility of using emotional engagement both as a legitimate ground for reasoning (Sayer, 2011) and as a subject of analysis. The role of values and emotions for the purposes of mobilisation and underpinning change has been rescued and discussed in philosophical, sociological and political science literatures (Sayer, 2011; Nussbaum, 2003; Pedwell, 2014; Clarke, Hoggett and Thompson, 2006). However, despite some notable exceptions (i.e., Valentine, 2009), and albeit the literature on the use of evidence in policy acknowledges moral values, their sources and impacts are under-theorised, and explanations tend to emphasise interests, rather than values.

Evidence continues to be seen by many as a useful tool which enables people to focus their thoughts away from their values and principles. Doing so might provide a middle ground for practical reasoning:

You to some extent separate out those beliefs that are probably not subject to change because they are very integral to your [...] world view [...] and so how you interpret the evidence can be [...] worked on [...] without having to require people to change their fundamental $[. .$. underpinning world view. (UK Researcher/Civil Servant 26)

The drug policy debate is an emotional realm, with polarised views associated with cognitive and emotional biases, morality and politics. In this context, some participants emphasised that anecdotes in the form of personal stories, due to their accessible, emotions-ridden nature, go further than scientific evidence in their ability to foster people's understanding of drug policy issues. Below, one participant claims that his story was a powerful driver in shifting audiences' attitudes towards drugs and drug use.

They say how much their attitude changed about drugs and drug use just by listening to my story and my presentation [...] I can speak to a group of people and I can actually change their minds about drug policy [...] I use the emotion, yeah, and it is effective (AU Advocate 10)

With a direct reference to using emotions, the participant exposes the potential of fostering emotional engagement for underpinning attitude change. Other participants who did not come from a scientific background and who more often dealt with lay audiences, told of how stories and personified accounts could move people more than numbers, even though, they said, one needs to use both. It is noteworthy that knowledge-brokers, advocates and activists, more so than researchers, are purposefully engaging audiences emotionally through the use of personal stories, aiming at empathic understanding of the issues drug users face.

Discussion: moral foundations, framing, and mobilising empathy. Among other outcomes, the rise of scientific over religious organisation of beliefs (Gieryn, 1983) contributed to shifting the moral domain away from the community and toward the individual in the west. Within this process, which affected both western liberals and conservatives (Haidt, 2013), liberals are 
certainly further attached to science as 'secular faith' (Boswell, 2018; Zampini, 2016), and to individual freedom as foundational in their value system (Haidt, 2013). The liberal to conservative spectrum is complex, and is characterised by varied, internally contradictory, and periodically changing positions, which do not easily align with either individualised or community-based loci of moral values (expressed as the individualising-binding dichotomy [Graham, Haidt and Nosek, 2009]).

Although the moral spectrum is not two-dimensional, and moral foundations theory was put forth in order to express moral complexity, it has been observed that the importance of certain moral foundations is greater for liberals than it is for conservatives. Specifically, liberals are more concerned with care, harm and fairness, whereas conservatives are more concerned with issues related with in-group protection (i.e., family or community), authority, loyalty and sanctity (Graham, Haidt and Nosek, 2009). According to Haidt (2013, p 181), not only can conservatives appeal to care and fairness, they also have 'a near monopoly' over authority, sanctity and loyalty; he calls this the 'conservative advantage'. Although conservatives may have been pioneers in investing in harm reduction (i.e., in the UK under Thatcher), this has been regarded as primarily motivated by a need to protect the in-group (i.e., the healthy, law-abiding population) from the threat of drugs and drug users (i.e., the infected/criminal population) (MacGregor, 2017). Conservatives would thus primarily rely on authority, sanctity, and loyalty as foundations to justify commitment to harm reduction. Though conservatives are indeed motivated by moral foundations of care and fairness, these are less primary because they exist in conjunction with other foundations, rather than reigning supreme, and as such they are interpreted and acted upon differently.

Liberals are comparatively unconcerned and even rejecting of loyalty, authority and sanctity as foundational to morality (Haidt, 2013). Liberals' positions in drug policy can be conceptualised as resting on two axes: a rights-based axis, framing arguments around the human rights of drug users, and a public health/ universal health axis, framing arguments around drug users' inequitable access to health. In moral foundations terms, the care and fairness foundations underpin these positions and are primary in shaping liberals' demands. Interestingly in harm reduction debates, the 'weak' right to health is advocated much more openly and widely than the 'strong' right to use drugs (Hunt, 2004). Other than the ability to justify the former through an evidence-based framing, this might also be tied to the individualistic nature of a rights-based argument, versus a public health frame's more universalist concern. It seems clear that openly advocating for the right to use drugs is perceived as a politically risky strategy.

According to Haidt (2013), liberal morality is problematic in terms of framing. Liberals may find it harder than conservatives to make explicitly moral arguments because of their contemporaneous commitment to the individual (and her/his freedom), as well as universalism, versus conservatives' commitment to community and in-group protection. As such, a public health framing may generally be perceived as more successful, and less morally controversial, than a rights-based framing. Conservatives, who can appeal to the full spectrum of moral foundations and are comparatively less concerned with individual freedom (Graham, Haidt and Nosek, 2009), may find it easier to explicitly frame their arguments in moral terms. Indeed, conservative arguments for recovery and abstinence are well supported by the moral foundations of sanctity, loyalty and authority (Stevens and Zampini, 2018).

A parallel view focusing on the relationship between morality and emotions is that of Lakoff (1996). He distinguishes a 'strict father' from a 'nurturant parent' morality. The former, associated with conservatives, is one that responds more strongly to fear and anxiety, whereas the latter is mobilised by empathy. Interestingly, a conservative morality as conceptualised by Lakoff is founded upon the mechanism of reward and punishment. He argues that 'rewards for obedience and punishments for disobedience are crucial to maintaining moral authority; as such, they lie at the heart of this moral system and are thus moral.' (1996, p 164). Drug policy is manifestly based on mechanisms of reward (for those who abstain) and punishment (for those who use). Conversely, Lakoff argues that, for liberals, 'the primacy of morality as empathy makes empathy a priority' (1996, p 166). Empathy is seen as a fundamental element of liberal morality. Lakoff follows on to argue that

'morality as fairness is a consequence; if you empathise with others, you will want them to be treated fairly. This makes empathetic actions and actions promoting fairness into moral actions. Consequently, a lack of empathetic behaviour, or actions going against fairness, are immoral' for liberals (ibid).

Empathy, fairness and care are characteristics of a liberal morality and can be associated with harm reduction, expressed as concern for people's health and rights.

As we have observed, some participants owed their commitment to harm reduction specifically to their experiential exposure, which enabled empathy and mobilised foundations of care and fairness. Advocates and knowledge brokers who more often dealt with lay audiences including politicians and the public, emphasised that evidence should not remain abstract (i.e., presented through "impersonal" data and statistics) but should be personified through life narratives to allow for emotions and empathy to play a role and "bring it home to people" (AU Knowledge Broker 3). By way of example, stakeholders have reported that drug-related deaths increased drastically in the past few years in the UK. However, there has been no further investment in harm reduction services despite the tireless work of advocates who are exposing the magnitude of the problem through numbers and headlines (ACMD, 2016; Dearden, 2017; BBC, 2017; EMCDDA, 2017).

An alternative strategy would be to frame this issue in terms of individual experiences, presenting case studies in the form of live documents, stories and life narratives of people living with, and dying from, addiction, alongside those numbers. In this way, whilst registering the scale of the problem through statistics, an emotional connection might be enabled, encouraging moral responses underpinned by empathy. If stakeholders' moral foundations are already skewed towards care and fairness, and if empathy is primary in the way that they operate, then advocates may have a good chance to garner support. If stakeholders' moral foundations are skewed towards authority, loyalty and sanctity, advocates may well have a more difficult task at hand. Yet, as moral foundation theorists posit, alternate foundations, albeit not primary, are still present and can be mobilised. This requires developing strategies around different moral framings that may appeal to different stakeholders in the debate.

\section{Conclusion}

In this article, I have argued that analysis of harm reduction in terms of morality provides an interesting angle to transcend the evidence/politics dualism that brought evidence-based policymaking to its impasse. Despite initial gains through the promotion of an amoral, economically driven harm reduction, political backing in both the UK and Australia is now waning in favour of less tolerant stances toward drug use, with much greater emphasis on recovery and abstinence, mounted on moral grounds (Berridge, 2012; Duke, 2013; Lancaster et al., 2015). Although fighting 
politics and morals with evidence might be perceived as advantageous on the surface, the extent to which value-neutral arguments manage to achieve value-driven goals is called into question. Partly through a process of de-moralisation, harm reduction lost its original objective-to ensure the health and rights of drug users - whilst becoming a compromised, moneysaving, crime-reducing set of measures deployed to fulfil interests outside those of drug users themselves (Hunt and Stevens, 2004).

The rapidly increasing number of opioid-related deaths in the UK over the past few years is testament of the disinvestment in strategies aimed at ensuring drug users' health and rights (ACMD; 2016). This evidence, despite being made manifest by evidence advocates, has been repeatedly downplayed and even ignored (Stevens, 2017). In Australia, a rising trend in fatal overdoses, and a parallel trend in the rise of the recovery discourse, have been identified (Roxburgh and Burns, 2012; Lancaster et al., 2015), while fluctuations in availability of heroin have made drugs such as OxyContin, and later more powerful drug Fentanyl, popular and deadly alternatives (Roxburgh et al., 2013).

The data analysed from England and New South Wales show some uniformity in terms of participants' agreement that evidence is a useful tool in drug policy debates in that it can render people less entrenched. Uniformity across the two countries is also visible in the manner stakeholders described their engagement in the drug policy debate. However, some important differences between participants were noted. Researchers and other stakeholders with a scientific or public service background were more likely to claim that their views are grounded in evidence. They shared a tendency to present morality as moralism, and as inimical to sound reasoning. On the other hand, advocates and knowledge brokers were more attuned to engaging morally and emotively. These actors suggested that, in their experience, what is more likely to spark commitment and understanding is experiential and personal in character, implying that values and emotions would be more obviously apparent. This goes against the perceived wisdom of neutralising emotions in favour of pursuing nominally value-free evidence. Ultimately, emotional engagement and value commitment need to accompany engagement with a subject and with relevant evidence.

Emotional engagement and value commitment thus encourage involvement and understanding, underpinning change. Developing better tools for analysing the role of morality, values and emotions in decision-making, engaging with insights from moral psychology alongside policy analysis, is paramount to the study of the politics of evidence-based policymaking. More specifically, the moral foundations framework highlights that morality operates differently depending on individuals' positions on the liberal/ conservative spectrum. This invites reflection on the way different moral foundations can be mobilised in harm reduction debates. Whereas conservatives appeal to all moral foundations (care, fairness, authority, loyalty and sanctity), liberals primarily appeal to care and fairness, rejecting other foundations. Furthermore, liberals respond more easily to empathy and conservatives are more easily mobilised by fear. This has implications for the way they may engage with drug policy debates and for the way advocates may wish to frame their arguments.

Evidence-based policy advocates who are reticent to be openly moral and engage audiences emotionally may find that, though initially successful, this strategy has limited gains. This is because the motivation behind people's commitment to drug policy and harm reduction rests on moral grounds, irrespective of whether the person is a researcher, an advocate, or a high-ranking politician. It is necessary to place this under further scientific scrutiny, as there is a tendency towards further polarisation, given the antagonism that arises from the split between a supposed evidence-based position and a supposed moral and political other.
Received: 26 July 2017 Accepted: 1 May 2018

Published online: 05 June 2018

\section{Notes}

1 Advisory Council on the Misuse of Drugs, is a UK statutory body that provides scientific advice on matters pertaining illicit drugs and their misuse. It was established in 1971 with the passing of the Misuse of Drugs Act.

\section{References}

ACMD (2016) Reducing opioid-related deaths in the UK. Home Office, London Archer M, Bhaskar R, Collier A, Lawson T, Norrie A (2013) Critical realism: essential readings. Routledge, London \& New York

BBC (2017) Drug deaths: Cocaine contributes to record number. http://www.bbc. co.uk/news/uk-40800288. Accessed 8 Jan 2018

Beirness D, Notarandrea R, Jesseman R, Perron M (2008) Reducing the Harm of "Harm Reduction. Clin Pharmacol Ther 83(4):523-525

Berridge V (2012) The rise, fall, and revival of recovery in drug policy. Lancet 379 (9810):22-23

Boswell J (2018) What makes evidence-based policy making such a useful myth? The case of NICE guidance on bariatric surgery in the United Kingdom. Governance 31(2):199-214

Clarke S, Hoggett P, Thompson S (eds) (2006) Emotion, politics and society. Palgrave Macmillan, UK

Coutinho RA (2000) Needle exchange, pragmatism, and moralism. Am J Public Health 90(9):1387-1388

Dearden L (2017) Drug deaths hit record high in England and Wales, new statistics show. The Independent. http://www.independent.co.uk/news/uk/homenews/drug-deaths-england-and-wales-3744-overdose-poisoning-legal-highsnew-psychoactive-substances-a7872241.html. Accessed 8 Jan 2018

Dee M (2013) Welfare surveillance, income management and new paternalism in Australia. Surveill Soc 11(3):272

Deeming C (2017) The lost and the new 'liberal world'of welfare capitalism: a critical assessment of Gøsta Esping-Andersen's the three worlds of welfare capitalism a quarter century later. Social Policy Soc 16(3):405-422

Duke K (2013) From crime to recovery: the reframing of British Drugs Policy? J Drug Issues 43(1):39-55

Duke K, Thom B (2014) The role of evidence and the expert in contemporary processes of governance: the case of opioid substitution treatment policy in England. Int J Drug Policy 25(5):964-971

EMCDDA (2017) European Drug Report. http://www.emcdda.europa.eu/system/ files/publications/4541/TDAT17001ENN.pdf. Accessed 8 Jan 2018

Engeli I, Green-Pedersen C, Larsen LT (2013) The puzzle of permissiveness: understanding policy processes concerning morality issues. J Eur Public Policy 20(3):335-352

Eriksson A, Pratt J (2014) Contrasts in punishment: an explanation of anglophone excess and Nordic exceptionalism. Routledge, London and New York

Esping-Andersen G (1990) The three worlds of welfare capitalism. Princeton University Press, Princeton

Evans G, Heath A, Lalljee M (1996) Measuring Left-Right and LibertarianAuthoritarian Values in the British Electorate. Br J Sociol 47(1):93

Evans D (2003) Hierarchy of evidence: a framework for ranking evidence evaluating healthcare interventions. J Clin Nurs 12(1):77-84

Ezard N (2001) Public health, human rights and the harm reduction paradigm: from risk reduction to vulnerability reduction. Int J Drug Policy 12 (3):207-219

Fischer J (2004) Social responsibility and ethics: clarifying the concepts. J Bus Ethics 52(4):381-390

Flanagan SC, Lee A-R (2003) The New Politics, Culture Wars, and The Authoritarian-Libertarian Value Change in Advanced Industrial Democracies. Comp Political Stud 36(3):235-270

Germov J (2005) Managerialism in the Australian public health sector: towards the hyper-rationalisation of professional bureaucracies. Sociol Health \& Illn 27 (6):738-758

Gieryn TF,(1983) Boundary-work and the demarcation of science from non-science: Strains and interests in professional ideologies of scientists Am Soc Rev 48(6):781-795

Global Commission on Drug Policy (2017) The World Drug Perception Problem: Prejudices about People who use Drugs. http://www.globalcommissionondrugs. org/reports/changing-perceptions/. Accessed 27 Apr 2018

Graham J, Haidt J, Nosek BA (2009) Liberals and conservatives rely on different sets of moral foundations. J Personal Social Psychol 96(5):1029-1046

Haidt J (2013) The righteous mind: why good people are divided by politics and religion. Vintage Books, New York 
Haider-Markel DP, Meier KJ (1996) The Politics of Gay and Lesbian Rights: Expanding the Scope of the Conflict. J Polit 58(2):332-349

Hathaway AD (2001) Shortcomings of harm reduction: toward a morally invested drug reform strategy. Int J Drug Policy 12(2):125-137

Haydock W (2015) UK substance use policy research should think local. Drugs Alcohol Today 15(3):149-157

Heichel S, Knill C, Schmitt S (2013) Public policy meets morality: conceptual and theoretical challenges in the analysis of morality policy change. J Eur Public Policy 20(3):318-334

Home Office (2010) Reducing Demand, Restricting Supply, Building Recovery: Supporting People to Live a Drug Free Life. Stationary Office, London

Hunt A (1999) Governing morals: a social history of moral regulation. Cambridge University Press, Cambridge

Hunt N (2004) Public health or human rights: what comes first? Int J Drug Policy 15(4):231-237

Hunt N, Stevens A (2004) Whose Harm? Harm Reduction and the Shift to Coercion in UK Drug Policy. Social Policy Soc 3(4):333-342

Keane H (2003) Critiques of harm reduction, morality and the promise of human rights. Int J Drug Policy 14(3):227-232

Knill C (2013) The study of morality policy: analytical implications from a public policy perspective. J Eur Public Policy 20(3):309-317

Lakoff G (1996) Moral politics: what conservatives know that liberal don't. Chicago, Chicago

Lancaster K, Duke K, Ritter A (2015) Producing the "problem of drugs": a cross national-comparison of "recovery" discourse in two Australian and British reports. Int J Drug Policy 26(7):617-625

Lenton S, Single E (1998) The definition of harm reduction. Drug Alcohol Rev 17 (2):213-219

Layder D (1998) Sociological practice: linking theory and social research. Sage, London

MacGregor S (1999) Welfare, neo-liberalism and new paternalism: Three ways for social policy in late capitalist societies. Capital \& Class 23(1):91-118

MacGregor S (2017) The politics of drugs: perceptions, power and policies. Palgrave Macmillan, UK

Marlatt GA (1996) Harm reduction: come as you are. Addict Behav 21(6):779-788

McKeganey NP (2011) Controversies in drugs policy and practice. Palgrave MacMillan, UK

Meier KJ (1999) Drugs, Sex, Rock, and Roll: A Theory of Morality Politics. Policy Stud J 27(4):681-695

MSIC Evaluation Committee (2003) Final Report on the Evaluation of the Sydney Medically Supervised Injecting Centre. http://www.indro-online.de/ sydneyfinalreport.pdf. Accessed 12 Jan 2018

Monaghan M (2010) The Complexity of Evidence: Reflections on Research Utilisation in a Heavily Politicised Policy Area. Social Policy Soc 9(1):1

Monaghan M (2011) Evidence Versus Politics: Exploiting Research in UK Drug Policy Making? Policy Press, Bristol; Portland, Ore

Mooney CZ (1999) The Politics of Morality Policy: Symposium Editor's Introduction. Policy Stud J 27(4):675-680

Naughton M (2005) "Evidence-based policy" and the government of the criminal justice system - only if the evidence fits! Crit Social Policy 25(1):47-69

Nussbaum MC (2003) Upheavals of thought: the intelligence of emotions. Cambridge University Press, Cambridge

Parkhurst J (2016) The Politics of Evidence: From Evidence-Based Policy to the Good Governance of Evidence

Pauly B (2008) Harm reduction through a social justice lens. Int J Drug Policy 19 (1):4-10

Pedwell C (2014) Affective relations: the transnational politics of empathy. Palgrave Macmillan, UK

Petticrew M, Roberts H (2003) Evidence, hierarchies, and typologies: horses for courses. J Epidemiol Community Health 57(7):527-529

Pollitt C (2016) Managerialism redux? Financ Account Manag 32(4):429-447

Ray JJ (1982) Authoritarianism/Libertarianism as the Second Dimension of Social Attitudes. J Social Psychol 117(1):33-44

Roe G (2005) Harm reduction as paradigm: Is better than bad good enough? The origins of harm reduction. Crit Public Health 15(3):243-250

Room R (2014) Legalizing a market for cannabis for pleasure: Colorado, Washington, Uruguay and beyond. Addiction 109(3):345-351

Roxburgh A, Burns L (2012) Accidental opioid-induced deaths in Australia 2008. National Drug and Alcohol Research Centre, Sydney

Roxburgh A, Burns L, Drummer OH, Pilgrim J, Farrell M, Degenhardt L (2013) Trends in fentanyl prescriptions and fentanyl-related mortality in Australia. Drug Alcohol Rev 32(3):269-275
Sayer RA (2011) Why things matter to people: social science, values and ethical life. Cambridge University Press, Cambridge

Skinner N, Feather NT, Freeman T, Roche A (2007) Stigma and discrimination in health-care provision to drug users: The role of values, affect, and deservingness judgments. J Appl Social Psychol 37(1):163-186

Stevens A (2007) Survival of the Ideas that Fit: An Evolutionary Analogy for the Use of Evidence in Policy. Social Policy Soc 6(1):25

Stevens A (2011) Drug policy, harm and human rights: a rationalist approach. Int J Drug Policy 22(3):233-238

Stevens A (2017) Principles, pragmatism and prohibition: explaining continuity and change in British drug policy. In: Liebling A, Maruna S, McAra L (eds) Oxford Handbook of Criminology, 6th Edn. Oxford University Press, Oxford, pp 825-842

Stevens A, Zampini GF (2018) Drug policy constellations: a Habermasian approach for understanding English drug policy. Int J Drug Policy 57:61-71

Strang J, Babor T, Caulkins J, Fischer B, Foxcroft D, Humphreys K (2012) Drug policy and the public good: evidence for effective interventions. Lancet 379 (9810):71-83

Taylor-Gooby P (2016) The Divisive Welfare State. Social Policy Adm 50 (6):712-733

Tilley JR (2005) Research Note: Libertarian-Authoritarian Value Change in Britain, 1974-2001. Political Stud 53(2):442-453

Valentine K (2009) Evidence, values and drug treatment policy. Crit Social Policy 29(3):443-464

Weiss CH (1979) The many meanings of research utilization. Public Adm Rev 39 (5): 426

Wodak A, Symonds A, Richmond R (2003) The role of civil disobedience in drug policy reform: how an illegal safer injection room led to a sanctioned, 'medically supervised injection center. J Drug Issues 33(3):609-623

Zampini GF (2014) Governance versus government: drug consumption rooms in Australia and the UK. Int J Drug Policy 25(5):978-984

Zampini G (2016) Morality Play: a comparative study of the use of evidence in drug and prostitution policy in Australia and the UK. PhD Thesis. University of Kent, Canterbury

\section{Data availability}

The data analysed during the current study are not publicly available to protect the anonymity and confidentiality of study participants. Consent was given by participants on the premise that their anonymity would be safeguarded.

\section{Acknowledgements}

The author would like to thank Camille Stengel, Alex Stevens, Alison Ritter, Phil Hubbard, Ben Hunter, and Deanna Dadusc for reading previous incarnations of this article.

\section{Additional information}

Competing interests: The author declares no competing interests.

Reprints and permission information is available online at http://www.nature.com/ reprints

Publisher's note: Springer Nature remains neutral with regard to jurisdictional claims in published maps and institutional affiliations.

Open Access This article is licensed under a Creative Commons Attribution 4.0 International License, which permits use, sharing, adaptation, distribution and reproduction in any medium or format, as long as you give appropriate credit to the original author(s) and the source, provide a link to the Creative Commons license, and indicate if changes were made. The images or other third party material in this article are included in the article's Creative Commons license, unless indicated otherwise in a credit line to the material. If material is not included in the article's Creative Commons license and your intended use is not permitted by statutory regulation or exceeds the permitted use, you will need to obtain permission directly from the copyright holder. To view a copy of this license, visit http://creativecommons.org/ licenses/by/4.0/

(c) The Author(s) 2018 